\title{
Peptide-based quorum sensing systems in Paenibacillus polymyxa
}

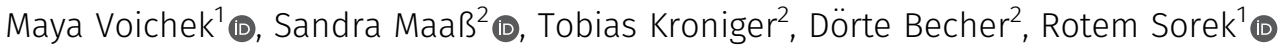

\begin{abstract}
Paenibacillus polymyxa is an agriculturally important plant growth-promoting rhizobacterium. Many Paenibacillus species are known to be engaged in complex bacteria-bacteria and bacteria-host interactions, which in other species were shown to necessitate quorum sensing communication. However, to date, no quorum sensing systems have been described in Paenibacillus. Here, we show that the type strain P. polymyxa ATCC 842 encodes at least 16 peptide-based communication systems. Each of these systems is comprised of a pro-peptide that is secreted to the growth medium and processed to generate a mature short peptide. Each peptide has a cognate intracellular receptor of the RRNPP family, and we show that external addition of $P$. polymyxa communication peptides leads to reprogramming of the transcriptional response. We found that these quorum sensing systems are conserved across hundreds of species belonging to the Paenibacillaceae family, with some species encoding more than 25 different peptide-receptor pairs, representing a record number of quorum sensing systems encoded in a single genome.
\end{abstract}

DOI $10.26508 /$ Isa.202000847 | Received 13 July 2020 | Revised 27 July 2020 | Accepted 28 July 2020 | Published online 6 August 2020

\section{Introduction}

Paenibacillaceae is a diverse family of bacteria, many of which are important in agricultural and clinical settings. These include Paenibacillus larvae, a pathogen causing the lethal American Foulbrood disease in honeybees (1), as well as Paenibacillus dendritiformis and Paenibacillus vortex, which are used as models for complex colony pattern formation $(2,3)$. Arguably, the best studied member of Paenibacillaceae is Paenibacillus polymyxa, known for its plant growth-promoting traits $(4,5,6)$. P. polymyxa produces a plethora of beneficial compounds, including the antibiotic polymyxin (7) and the phytohormone indole-3-acetic acid (IAA) (8), and was shown to protect multiple plant species against pathogens (reviewed in reference 9 ). Because of its beneficial traits, $P$. polymyxa is commercially used as a soil supplement to improve crop growth $(10,11)$.
Many of the characteristic features associated with the abovementioned behaviors-production and secretion of antimicrobials, expression of virulence factors, and forming complex colony structures-often require some form of intercellular communication such as quorum sensing (12). Bacteria use quorum sensing to coordinate gene expression patterns on a population level. For example, the quorum sensing network of Pseudomonas aeruginosa controls the production of secreted toxins as well as the production of rhamnolipids, which are important for its biofilm architecture (13, 14). Quorum sensing regulates the production of bacteriocin antimicrobials in Lactobacilli (15) and Streptococci $(16,17)$, and in Bacillus subtilis, quorum sensing systems play a major role in sporulation, biofilm formation, and genetic competence (18). Although Paenibacillus bacteria are engaged in similar behaviors, no quorum sensing was reported in any Paenibacillus species to date.

Gram-positive bacteria frequently use short peptides, termed autoinducer peptides, as their quorum sensing agents (12). A widespread group of such peptide-based communication systems involves intracellular peptide sensors (receptors) of the RRNPP family, together with their cognate peptides (19). Peptides of these quorum sensing systems are secreted from the cell as pro-peptides and are further processed by extracellular proteases (20) to produce a mature short peptide, usually 5-10 aa long $(19,21)$. The mature peptides are reinternalized into the cells via the oligopeptide permease transporter $(22,23)$ and bind their intracellular receptors $(24)$. These receptors act either as transcription factors or as phosphatases, and peptide binding activates or represses their function eventually leading to modulation of the bacterial transcriptional program. For example, in $B$. subtilis, the Rap receptors function as phosphatases that regulate the major transcription factor Spo0A; upon binding to their cognate Phr peptides, the phosphatase activity of Rap receptors is inhibited, leading to activation of SpoOA that alters the transcriptional program $(25,26)$. In Bacillus thuringiensis, the PlcR receptor is a transcription factor that becomes activated when bound to its cognate PapR peptide, leading to expression of virulence factors that facilitate infection of its insect larval host (27). Such peptide-based communication was recently shown also to control the lysis-lysogeny decision of phages infecting many species of Bacillus $(28,29)$.

${ }^{1}$ Department of Molecular Genetics, Weizmann Institute of Science, Rehovot, Israel ${ }^{2}$ Department of Microbial Proteomics, Institute of Microbiology, Center for Functional Genomics of Microbes, University of Greifswald, Greifswald, Germany 
Here, we report the identification of a large group of peptidebased quorum sensing systems in P. polymyxa. We found that propeptides of these systems are secreted and further processed and that the mature peptides modulate the transcriptional program of $P$. polymyxa. We further show that these quorum sensing systems are conserved throughout the Paenibacillaceae family of bacteria, with some bacteria encoding more than 25 different peptidereceptor pairs in a single genome.

\section{Results}

Identification of RRNPP-like peptide-receptor pairs in $P$. polymyxa ATCC 842

All members of the RRNPP family of intracellular peptide receptors contain a C-terminal tetratricopeptide repeat (TPR) or TPR-like domain, which forms the peptide-binding pocket in the receptor protein $(19,30)$. To search for such possible quorum sensing systems in P. polymyxa, we first scanned all annotated protein-coding genes of the type strain P. polymyxa ATCC 842 (31) for TPR domains using TPRpred (32) (see the Materials and Methods section). As TPR domains are found in diverse protein types, we manually analyzed the genomic vicinity of the identified TPR-containing proteins to search for a peptide-encoding gene characteristic of quorum sensing systems. We found two TPR domain genes that were immediately followed by a short open reading frame with a predicted $\mathrm{N}$-terminal hydrophobic helix, typical of a signal peptide that targets the pro-peptide for secretion (33) (Fig 1A). Two-gene operons that encode the receptor followed by its cognate peptide are a hallmark of many known members of the RRNPP family of quorum sensing systems (19).

We then used BLAST to search for additional homologs of the two putative TPR domain receptors in the P. polymyxa ATCC 842 genome

A

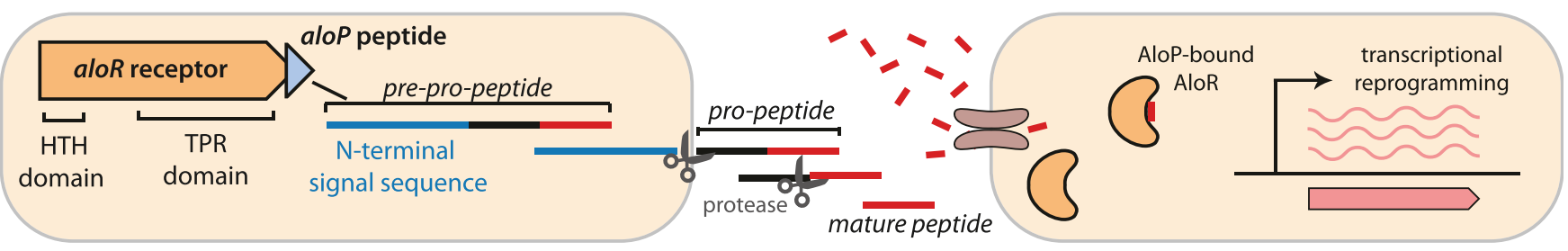

B

\begin{tabular}{|c|c|c|c|}
\hline System & AloR locus & AloP small ORF & AloP small ORF sequence \\
\hline Alo1 & PPTDRAFT_00471 & AloP1 (32 aa) & MLRKIGLLIVASSELVFMTVPGIQILVQVGGS \\
\hline Alo2 & PPTDRAFT_00474 & AloP2 (40 aa) & MLKKTVLLIIAASFLLFIVTVPDQAFNHHSIQPQVTIGGA \\
\hline Alo3 & PPTDRAFT_01046 & AloP3 (41 aa) & MIKKMAFCLAVTSELLVFTVPAQTANLSHGTIQVQGHIGGS \\
\hline Alo4 & PPTDRAFT_01711 & AloP4 (41 aa) & MKRKIILTILVTSFMLLTLVNPSAGYQNSEHNYEPAQHGEM \\
\hline Alo5 & PPTDRAFT_01713 & $(*)$ & \\
\hline Alo6 & PPTDRAFT_01722 & AloP6 (49 aa) & MKRLIKGLFATTFLLVFIASTQTINLQDFGMPQAFSNGGFSVFGWHIGS \\
\hline Alo7 & PPTDRAFT_02243 & AloP7 (35 aa) & MKKLISRPLSLSLFSLLVFVTSHDLITVFYHGANH \\
\hline Alo8 & PPTDRAFT_02798 & AloP8 (36 aa) & MLKKMALLIVASSFLFFITGPVLTQHIQILVQIGGA \\
\hline Alo9 & PPTDRAFT_02818 & AloP9 (40 aa) & MFKKVVLLIIAASFLLIVTVPDQAFNHHHSIQPNVTIGGF \\
\hline Alo10 & PPTDRAFT_03195 & $\begin{array}{l}\text { AloP10a (40 aa) } \\
\text { AloP10ß (40 aa) }\end{array}$ & $\begin{array}{l}\text { MLRKMALLIVATSFLFIVTLPVQTDGQHQNIVLYDQHGGA } \\
\text { MLKKTVMLIIASSFLFTLAVPIYVDGHIGGFQVFATHGGA }\end{array}$ \\
\hline Alo11 & PPTDRAFT_04223 & AloP11 (43 aa) & MKKKMVFFLAVSEGLMFVASAQLPFEQHQASGLISTQGYIGGA \\
\hline Alo12 & PPTDRAFT_04756 & $(*)$ & \\
\hline Alo13 & PPTDRAFT_04976 & AloP13 (44 aa) & MKKVFLSLLLSLIVVSNIGNLSYFHNITIGNGSQITVSSHGRGG \\
\hline Alo14 & PPTDRAFT_04977 & $(*)$ & \\
\hline Alo15 & PPTDRAFT_05290 & AloP15 (43 aa) & MKKALSS ITMVLAFLSVALPIGNTLGDLDSVHPSNHGVFSFTA \\
\hline Alo16 & PPTDRAFT 05358 & AloP16 (50 aa) & MIKKIVFSLLAFNVFILLNFPPVTPPIEDPSDVHSHGLGGWALSSPEPSA \\
\hline
\end{tabular}

Figure 1. Alo systems identified in P. polymyxa.

(A) Schematic representation of aloR-aloP operon organization and putative peptide processing. HTH, helix-turn-helix; TPR, tetratricopeptide repeat. (B) Alo loci identified in P. polymyxa ATCC 842. For the aloR receptor genes, the locus tag in the Integrated Microbial Genomes (IMG) database (49) is specified. Blue sequence in AloP peptides represents the predicted $\mathrm{N}$-terminal signal sequence for secretion, as predicted by Phobius (50) (see the Materials and Methods section). Asterisks ( ${ }^{\star}$ ) mark cases in which the aloP gene was absent or found as a degenerate sequence. 
(see the Materials and Methods section). This search revealed 14 additional homologous genes that were not initially recognized by TPRpred, in most cases because their C-terminal TPR domains were divergent and did not pass the default threshold of the TPRpred software (Supplemental Data 1). We found that all but three of the homologs had a short ORF (32-50 aa) encoded immediately downstream to them. We denote these putative communication systems as Alo (Autoinducer peptide Locus), with predicted Alo receptor genes designated aloR and the cognate peptide-encoded gene aloP. We number Alo loci in the P. polymyxa ATCC 842 genome from alo1 to alo16 (Fig 1B).

\section{Alo systems are ubiquitous in P. polymyxa strains}

Examining the genomes of 13 additional $P$. polymyxa strains using sequence homology searches revealed that the predicted Alo systems are conserved in the P. polymyxa lineage (Fig 2A; see the Materials and Methods section). Some of the Alo receptors (e.g., AloR3, AloR4, AloR7, AloR13, AloR15, and AloR16) are highly conserved and appeared in all $P$. polymyxa strains examined. Others appeared variably and were absent from some genomes (Fig 2B). We also found six additional putative peptide-receptor pairs that were not present in $P$. polymyxa ATCC 842 but were detectable in other strains; we denote these as Alo17-22 (Fig 2). Similar observations regarding "conserved" and "variable" quorum sensing systems were reported for peptide-based systems in other bacteria, for example, in the case of B. subtilis rap-phr genes, rapA-phrA and rapC-phrC are found to be conserved among $B$. subtilis species, whereas other systems, including rapE-phrE, rapl-phrl, and rapK-phrK, occur variably and are often located within mobile genetic elements (34).

In the vast majority of cases, aloR genes in the various $P$. polymyxa strains were found just upstream to a peptide-encoding aloP gene with an $\mathrm{N}$-terminal hydrophobic helix predicted to target them for secretion (Table S1). Exceptions were aloR18, for which we could not find a cognate downstream short ORF, and aloR5 and aloR14 in which degenerated peptide sequences were observed. In the Alo12 clade, we could identify a conserved short ORF in most $P$. polymyxa strains (excluding the type strain ATCC 842), yet it lacked the characteristic hydrophobic N-terminal signal sequence marking it for secretion. Orphan receptors, which lack a cognate peptide, have also been observed for RRNPP quorum sensing systems in other bacteria $(34,35)$.

To understand how common Alo systems are in bacteria, we performed an exhaustive profile-based search for AloR-like proteins in $>38,000$ bacterial and archaeal genomes (see the Materials and Methods section). This search yielded 1,050 hits in 149 bacteria, essentially all of which belong to the Paenibacillaceae family (Table S2). These included species of Paenibacillus, Brevibacillus, Saccharibacillus, Fontibacillus, and Gorillibacterium. The largest number of Alo receptors found in a single organism was in Paenibacillus terrae NRRL B-30644, in which 40 such receptors were
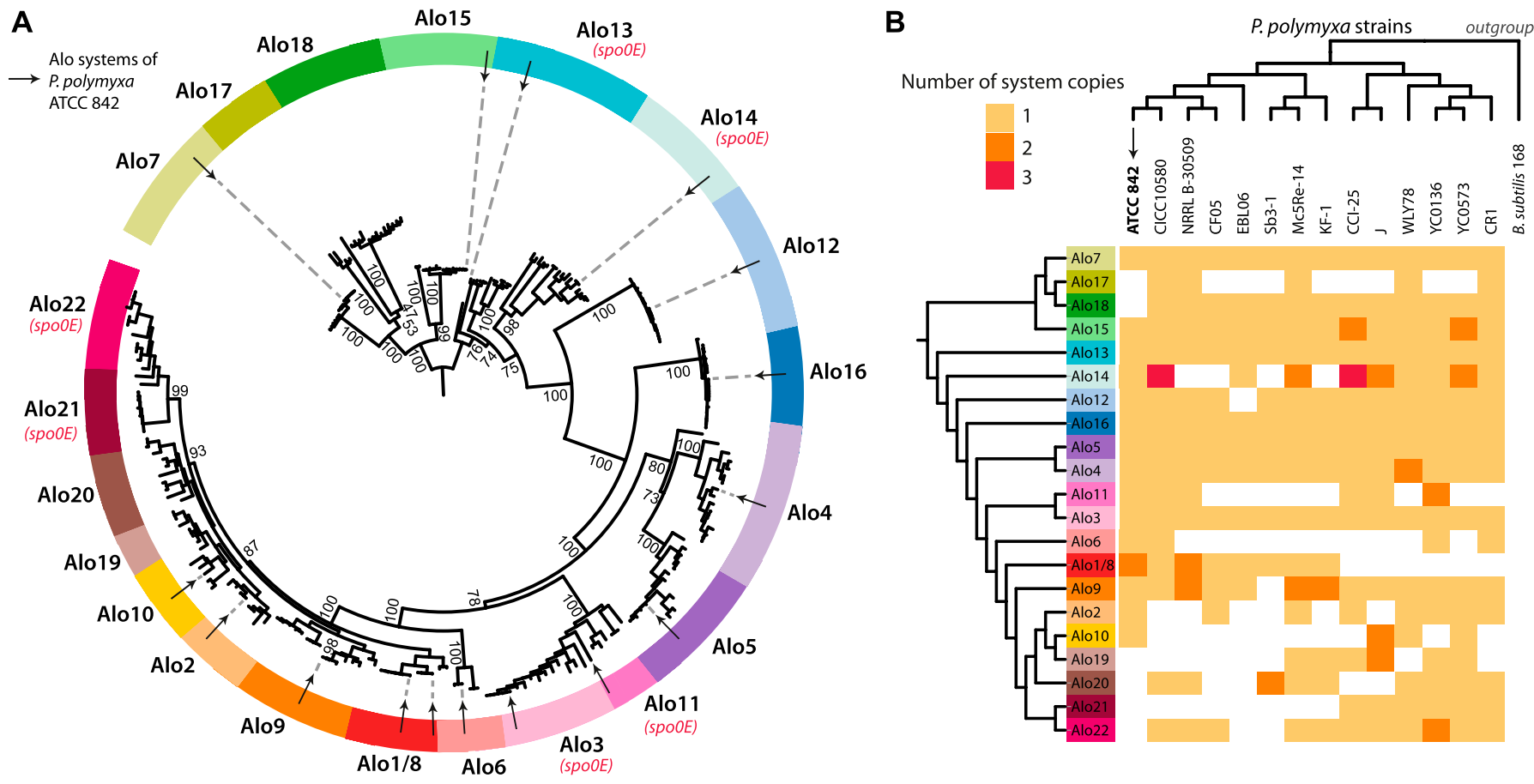

Figure 2. Phylogenetic distribution of Alo systems among $P$. polymyxa strains.

(A) Phylogenetic tree of 234 AloR homologs found in 14 P. polymyxa strains. Colored segments in the tree circumference define clades of AloR proteins corresponding to the systems found in P. polymyxa ATCC 842 (labeled as arrows). Systems immediately followed by a Spo0E-like protein are indicated. Tree was constructed using IQ-Tree $(55,56,57)$ with 1,000 iterations, and ultrafast bootstrap support values are presented for major branches. Tree visualization was done with iTOL (58). Alo1/8 refers to a system duplicated in P. polymyxa ATCC 842 (where it is represented as Alo1 and Alo8). (B) Frequency and distribution of Alo systems in P. polymyxa strains. The number of copies per Alo system found within P. polymyxa strains is shown using colored squares. The absence of an Alo system in a specific strain is marked by a white square. (A) Phylogenetic tree of the Alo systems shown on the vertical axis is derived from the tree in the panel (A). Phylogenetic tree of the strains shown on the horizontal axis is based on the GyrA protein, with GyrA from B. subtilis 168 as an out-group. 
detected (with cognate peptide-encoding genes detected immediately downstream to 27 of them, Table S3). These results suggest that the Alo system is a widespread quorum sensing system in bacteria belonging to the Paenibacillaceae family.

\section{Mass spectrometry (MS) analysis detects secretion and processing of pro-peptides}

Signaling peptides associated with quorum sensing regulators of the RRNPP family are known to be secreted into the growth medium as pro-peptides. The pro-peptides are further processed by extracellular proteases to generate the mature communication peptide (26, 36) (Fig 1A). To determine whether Alo peptides are similarly secreted, we analyzed growth media taken from P. polymyxa cultures using MS. For this, we grew P. polymyxa ATCC 842 in defined media, removed the bacteria by centrifuging, and took the supernatant (presumably containing the secreted peptides) for MS analysis. Notably, MS was performed without subjecting the peptides to trypsin treatment, to allow detection of peptides in their natural form. We were able to reproducibly detect various fragments of nine out of the 14 Alo peptides predicted in P. polymyxa ATCC 842 (Fig 3 and Table S4). In all cases, the fragments included the $\mathrm{C}$ terminus of the Alo peptide but not the $\mathrm{N}$ terminus, confirming that the $\mathrm{N}$ terminus is cleaved during or after the pro-peptide secretion, possibly by a signal peptidase associated with the Sec system (37). As a control, we repeated the same procedure on cultures of $B$. subtilis and found that the B. subtilis Phr peptides were also detectable in the MS analysis, with the same patterns of absent N-termini (Fig 3A and Table S4). In both B. subtilis and $P$. polymyxa, MS data indicated multiple possible cleavage sites within the $\mathrm{N}$-terminal signal sequence, as was previously reported also for other Gram-positive bacteria (38) (see the Discussion section). These results show that Alo peptides are secreted to the medium akin to other cases of RRNPP quorum sensing systems.

Following the secretion process, B. subtilis $\mathrm{Phr}$ peptides are known to be processed further to yield the mature 5-aa peptide. The mature peptide is usually found at the extreme C-terminal end of the pro-peptide, such that it may be released by a single cleavage event (Fig 3A). Such short peptides are challenging to identify using current MS pipelines (39) and indeed our MS analysis of B. subtilis conditioned media did not detect the mature 5-aa Phr peptides but rather revealed the $\mathrm{Phr}$ pro-peptides with the known mature peptide missing (Fig 3A). The absence of a short peptide from the $C$ terminus of the pro-peptide is therefore a clear signature of the processing event that releases the mature peptide. We were able to detect similar processing events in the P. polymyxa peptides as well (Fig 3B). These patterns strongly suggest that some of the AloP proteins generate 6 -aa communication peptides, whereas others generate presumably longer mature peptides (Fig 3B).

\section{Peptide-mediated modulation of the bacterial transcriptional program}

All Alo receptors contain a helix-turn-helix DNA-binding domain at their $\mathrm{N}$ terminus (Fig $1 \mathrm{~A}$ ), suggesting that they may function as
A

\begin{tabular}{|c|c|c|}
\hline Phr & Identified fraqment of Phr protein & $\begin{array}{l}\text { No. of } \\
\text { spectra }\end{array}$ \\
\hline PhrA & MKSKWMSGLLLVAVGFSFTQVMVHAGETANTEGKTFHIAARNQT & 3 \\
\hline PhrC & MKLKSKLFVICLAAAAIFTAAGVSANAEALDFHVTERGMT & 6 \\
\hline PhrC & MKLKSKLFVICLAAAAIFTAAGVSANAEALDFHVTERGMT & 6 \\
\hline PhrF & MKLKSKLLLSCLALSTVFVATTIANAPTHOIEVAQRGMI & 14 \\
\hline PhrF & MKLKSKLLLSCLALSTVFVATTIANAPTHOIEVAORGMI & 9 \\
\hline PhrG & MKRFLIGAGVAAVILSGWFIADHOTHSOEMKVAEKMIG & 2 \\
\hline PhrG & MKRFLIGAGVAAVILSGWFIADHOTHSOEMKVAEKMIG & 1 \\
\hline PhrH & $\begin{array}{l}\text { MPIKKKVMMCLAVTLVFGSMSFPTLTNSGGEKESTDRNTTYIDH } \\
\text { SPYKLSDQKKALS }\end{array}$ & 3 \\
\hline PhrH & $\begin{array}{l}\text { MPIKKKVMMCLAVTLVFGSMSFPTLTNSGGFKESTDRNTTYIDH } \\
\text { SPYKLSDQKKALS }\end{array}$ & 2 \\
\hline Phrl & MKISRILLAAVILSSVFS ITYLOSDHNTEIKVAADRVGA & 1 \\
\hline Phrl & MKISRILLAAVI LSSVFS ITYLOSDHNTE IKVAADRVGA & 1 \\
\hline PhrK & MKKLVLCVSILAVILSGVALTOLSTDSPSNIOVAERPVGG & 6 \\
\hline Phrk & MKKLVLCVSILAVILSGVALTQLSTDSPSNIQVAERPVGG & 4 \\
\hline
\end{tabular}

B

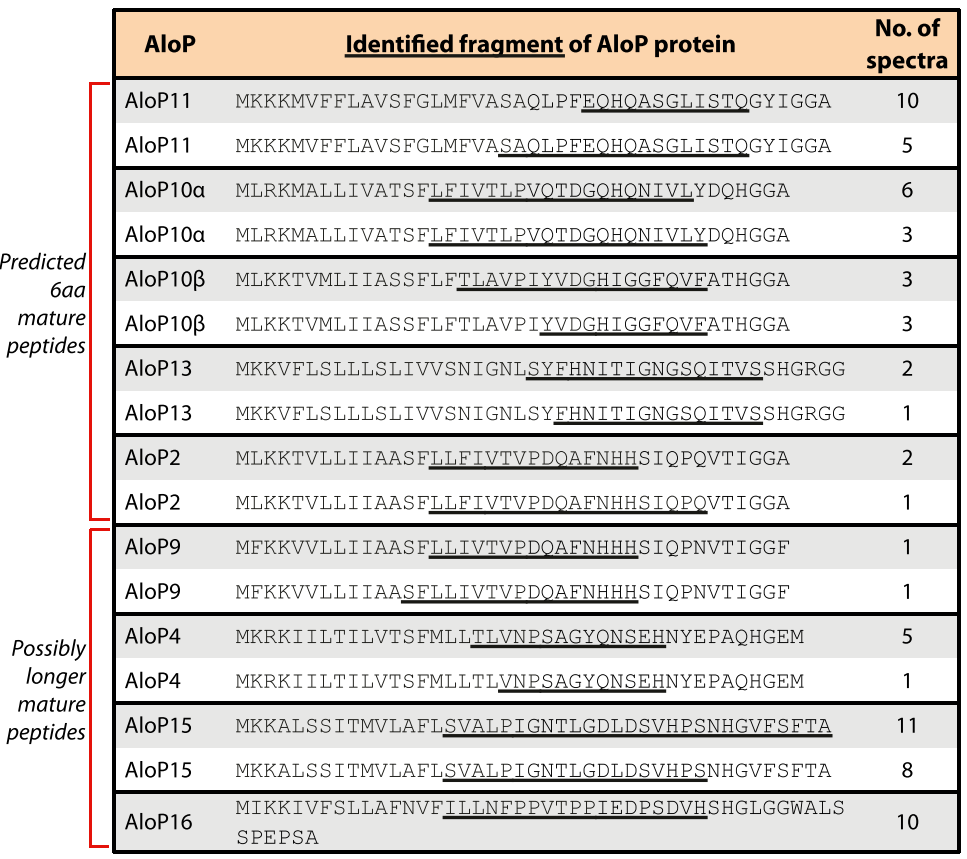

Figure 3. Mass spectrometry (MS)-based identification of secreted communication peptides.

(A) Phr peptide fragments detected in the growth media of B. subtilis 168. Peptide fragments identified by MS are underlined, with the cumulative number of spectra detected in all tested repeats indicated (see the Materials and Methods section). Known mature communication peptides are in red (26, 45). The two most abundantly identified fragments are presented for each protein by an underline. The mature peptides which were not directly detected are inferred from the C-terminal sequence of the full peptides, presumably after processing. (B) AloP peptide fragments detected by MS. Same as (A) for AloP peptide fragments detected in the growth media of P. polymyxa ATCC 842. 
transcriptional regulators similar to many members of the RRNPP peptide receptors family $(19,24)$. These regulators become activated or repressed once bound by their cognate peptides, leading to alteration of the transcriptional program in response to the quorum sensing peptides. To examine whether Alo peptides affect the transcriptional program of P. polymyxa, we selected Alo13, one of the systems conserved across all P. polymyxa strains, for further experimental investigation. The sequence of the mature AloP13 peptide, as predicted by the MS analysis, is SHGRGG (Fig 3B). Aiming to measure the immediate transcriptional response to the peptide, we incubated early log-phase-growing $P$. polymyxa cells with $5 \mu \mathrm{M}$ of synthetic SHGRGG peptide for 10 min. RNA-seq analysis of cells harvested after this short incubation with the peptide identified a set of 10 genes whose expression became significantly reduced when the peptide was added (Fig 4 and Table S5). This transcriptional response was not observed when a scrambled version (GRGSGH) of the mature AloP13 peptide was added to the medium, indicating that the transcriptional response is specific to the sequence of AloP13 (Table S6).

The most significant reduction in expression was in a gene annotated as Spo0E-like sporulation regulatory protein, whose expression was reduced by 4.5 -fold on average in response to the
A

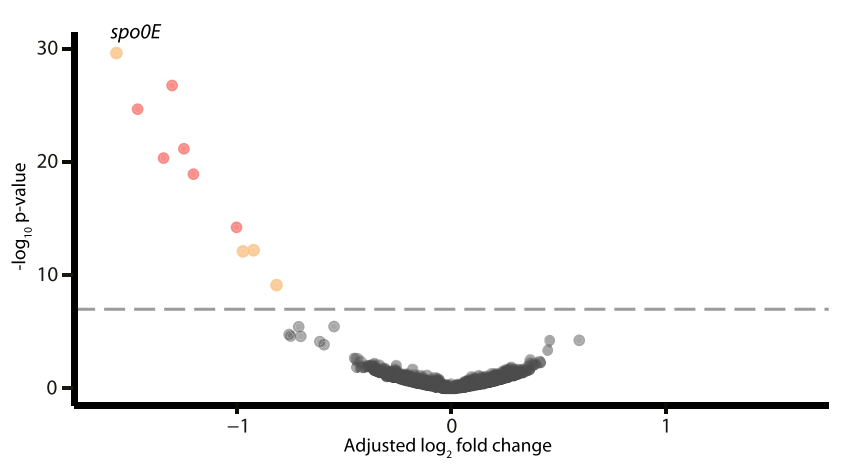

C

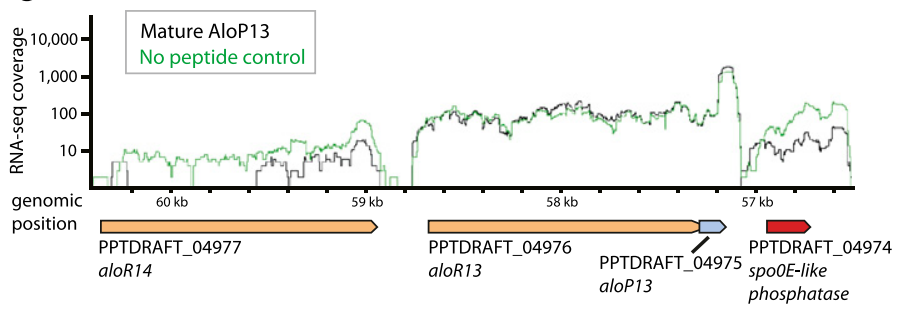

E

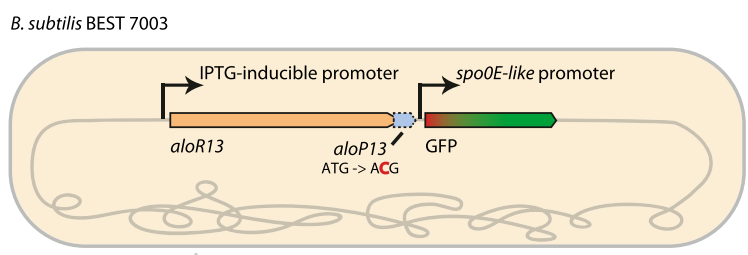

B

\begin{tabular}{|llccc|}
\hline Gene locus tag & Gene annotation & $\begin{array}{c}\text { Fold reduction } \\
\text { in expression }\end{array}$ & p-value & p-adjusted \\
\hline PPTDRAFT_04974 & $\begin{array}{l}\text { Spo0E-like sporulation } \\
\text { regulatory protein }\end{array}$ & 4.5 & $2.4 \times 10^{-30}$ & $1.1 \times 10^{-26}$ \\
\hline PPTDRAFT_04977 & AloR14 receptor & 4.2 & $2.2 \times 10^{-25}$ & $3.4 \times 10^{-22}$ \\
\hline PPTDRAFT_00475 & AloP2 peptide & 3.9 & $4.5 \times 10^{-21}$ & $4.2 \times 10^{-18}$ \\
\hline PPTDRAFT_03194 & AloP10 $\alpha$ peptide & 3.1 & $6.8 \times 10^{-22}$ & $7.9 \times 10^{-19}$ \\
\hline PPTDRAFT_03193 & AloP10 peptide & 3.0 & $1.7 \times 10^{-27}$ & $4.1 \times 10^{-24}$ \\
\hline AloP1_peptide & AloP1 peptide & 3.0 & $1.2 \times 10^{-19}$ & $9.2 \times 10^{-17}$ \\
\hline AloP8_peptide & AloP8 peptide & 2.4 & $5.8 \times 10^{-15}$ & $3.9 \times 10^{-12}$ \\
\hline PPTDRAFT_04979 & Hypothetical protein & 2.4 & $7.8 \times 10^{-13}$ & $4.0 \times 10^{-10}$ \\
\hline PPTDRAFT_00144 & $\begin{array}{l}\text { Sugar diacid utilization } \\
\text { regulator }\end{array}$ & 2.2 & $6.1 \times 10^{-13}$ & $3.6 \times 10^{-10}$ \\
\hline PPTDRAFT_01040 & $\begin{array}{l}\text { Signal transduction } \\
\text { histidine kinase }\end{array}$ & 2.1 & $7.4 \times 10^{-10}$ & $3.4 \times 10^{-7}$ \\
\hline
\end{tabular}

D

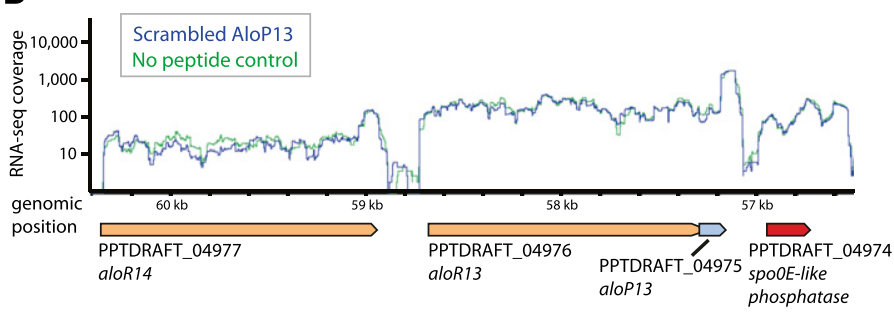

$\mathbf{F}$

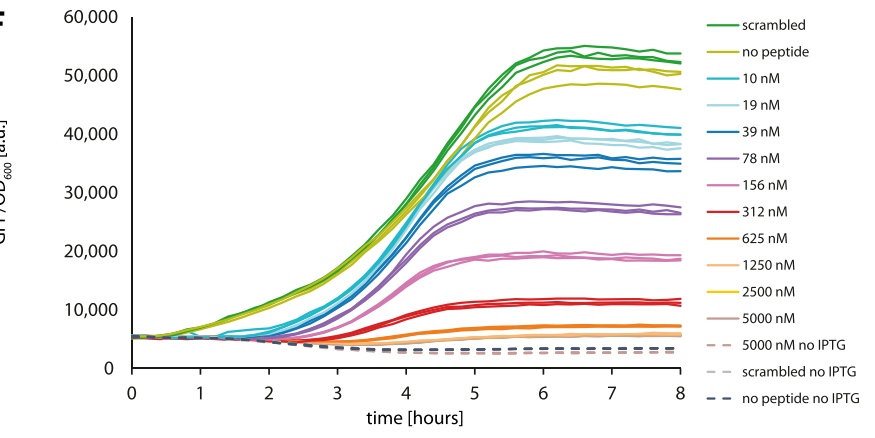

Figure 4. The mature AloP13 peptide elicits an immediate transcriptional response.

(A) Volcano plot depicting P. polymyxa gene expression after incubation with $5 \mu \mathrm{M}$ of the peptide SHGRGG for 10 min, as compared to control conditions in which no peptide was added. X-axis, log fold expression change (adjusted using the IfcShrink function in the DESeq2 R package (62); see the Materials and Methods section). Y-axis, $-\log _{10} P$-value. Average of three independent replicates; each dot represents a single gene. Dots appearing in colors are genes that passed the threshold for statistical significance of differential expression (see the Materials and Methods section). Red dots correspond to genes encoded by Alo systems. (B) Differentially expressed genes as appears in panel (A). Fold change represents the average of the three independent replicates. P-adjusted is the P-value after correction for multiple hypothesis testing (see the Materials and Methods section). (C) RNA-seq coverage of the Alo13-Alo14 locus (Scaffold: PPTDRAFT_AFOX01000049_1.49), in control conditions (green) or $10 \mathrm{~min}$ after addition of $5 \mu \mathrm{M}$ of the SHGRGG peptide (black). RNA-seq coverage is in log scale and was normalized by the number of uniquely mapped reads in each condition. Representative of three independent replicates. (D) RNA-seq coverage of the Alo13-Alo14 locus in control conditions (green) or $10 \mathrm{~min}$ after addition of $5 \mu \mathrm{M}$ of a scrambled version (GRGSGH) of the AloP13 peptide. RNA-seq coverage is in log scale and normalized as in the panel (C). Representative of three independent replicates. (E) Schematic representation of the genetic construct used in B. subtilis to verify the activity of AloR13. The start codon of the aloP13 gene (dashed blue arrow) was mutated to inactivate it. GFP was placed as a reporter gene instead of the SpO0E ORF. (F) GFP fluorescence upon addition of the AloP13 peptide SHGRGG in varying concentrations, or the scrambled mature peptide GRGSGH in $5 \mu \mathrm{M}$ ("scrambled"), or no peptide added. Dashed lines represent GFP fluorescence measured without the addition of IPTG. 
peptide (3.7-, 6-, and 4-fold reduction in the three independent replicates of the experiment) (Fig 4B). This reduction was also verified by reverse transcription quantitative real-time PCR (RTqPCR) (Fig S1). In B. subtilis, Spo0E functions as a phosphatase that regulates $S p \circ 0 A$, the master transcription factor for sporulation, thus inhibiting the initiation of the sporulation pathway (40). Interestingly, the $5 P O O E$-like gene is encoded directly downstream to the Alo13 locus in P. polymyxa (Fig $4 \mathrm{C}$ and D). These results imply that the immediate effect of the AloP13 quorum sensing peptide involves down-regulation of the spo0E-like gene, which likely leads to a further regulatory cascade at later time points. We note that spo0E-like genes occur immediately downstream of 6 Alo systems in P. polymyxa (Fig 2A) and downstream to 12 of the P. terrae Alo systems (Table S3). This conserved genomic organization suggests that many Alo systems may exert their effect on the cell by modulating the expression of Spo0E-like regulatory phosphatase proteins. Notably, a similar regulatory architecture is observed in the arbitrium RRNPP communication module that regulates phage lysogeny decisions, where the binding of the arbitrium peptide to its AimR receptor also leads to down-regulation of the immediate downstream gene, aimX (28).

Most of the additional genes whose expression became reduced following $10 \mathrm{~min}$ of exposure to the AloP13 mature peptide were those encoding other AloP peptides, including aloP1, aloP2, aloP8, aloP10 $\alpha$, and aloP10 $\beta$, as well as the gene encoding the receptor aloR14 that is encoded adjacent to the aloR13 gene (Fig 4). These results suggest that as in other bacteria $(35,41)$, quorum sensing systems can sometime cross-regulate other such systems in $P$. polymyxa. Combined, these results suggest that the AloP13 mature peptide affects the transcription of specific target genes and verifies Alo systems as quorum sensing systems in P. polymyxa.

To verify that the SPOOE gene is indeed directly controlled by the Alo system, we cloned the entire alo13 locus into the genome of $B$. subtilis, but replaced the spoOE gene with a GFP reporter (Fig 4E). As shown in Fig 4F, activation of the AloR expression results in accumulation of the GFP signal, indicating that AloR positively controls the Spo0E promoter. However, external addition of the mature AloP peptide SHGRGG resulted in reduction of GFP expression, in a manner directly dependent on the peptide concentration, with a near-complete shutoff of GFP expression observed when $5 \mu \mathrm{M}$ of peptide was added. Expression reduction was observed when as little as $10 \mathrm{nM}$ of SHGRGG peptide was added, which is parallel to activities observed for other RRNPP systems (28). Moreover, addition of the scrambled version of the AloP peptide (GRGSGH) did not affect GFP expression, showing that the effect of the peptide on AloR activity is sequence specific as in other RRNPP systems (35). Overall, these results verify that the Alo13 peptide-receptor system directly controls the expression of the downstream Spo0E protein.

\section{Discussion}

In this work, we identified a large family of putative peptide-based quorum sensing systems in Paenibacillaceae bacteria and functionally characterized one of these systems in the type strain $P$. polymyxa ATCC 842. We found that the peptide precursors are secreted to the growth medium and further processed to form putatively mature communication peptides which lead to transcriptional reprogramming. The large number of such systems in a single bacterium (16 in P. polymyxa ATCC 842 and at least 27 in P. terrae) suggests that Paenibacillus may need an unusually large amount of signals to coordinate their complex social traits. Previous studies have predicted that $P$. polymyxa strains may also use Al-2 quorum sensing, based on the presence of components of the Al-2 pathway in its genome, although the production of Al-2 by $P$. polymyxa was not detected $(42,43)$. In addition, P. polymyxa ATCC 842 was found to encode an agr-like gene cassette that is homologous to another peptide-based communication system in staphylococci (44). Together with our discovery of the Alo communication systems, to our knowledge, Paenibacillus have the largest number of quorum sensing systems reported in any bacteria to date.

Interestingly, none of the Alo systems discovered possess strong sequence similarity to any of the other known RRNPP systems, and hence, they were not identified in previous searches (e.g., see reference 19, and Fig S2). We believe the domain-based analysis strategy that we used to identify TPR-containing genes, rather than direct sequence homology searches, enabled the discovery of additional distant members of the RRNPP family of receptors. It is possible that usage of a similar search strategy on genomes of Gram-positive bacteria may lead to the discovery of additional RRNPP systems.

Previous studies on quorum sensing systems in other bacteria focused on isolating and characterizing the mature signaling peptide. Our MS-based approach identified, for the first time, the pro-peptide remainders that are found in the extracellular medium after secretion, in both $B$. subtilis and P. polymyxa. Curiously, the MS spectra suggest that the hydrophobic $\mathrm{N}$-terminal signal sequence can be cleaved in multiple positions, a phenomenon that has been reported in other Gram-positive bacteria such as Staphylococcus aureus (38).

In B. subtilis, most Phr pro-peptides are processed by a single protease cleavage event, releasing the $\mathrm{C}$-terminal mature peptide. However, in some cases, there are two cleavage events (e.g., $\mathrm{PhrH}$ and PhrK), releasing an internal portion of the pro-peptide to form the mature communication peptide $(26,45)$. Our MS data of $B$. subtilis peptides show that these cases may not be detectable in our analyses, but instead may appear as longer mature peptides (see PhrH and Phrk in Fig 3A). It is therefore conceivable that some of the AloP peptides in P. polymyxa, especially the ones for which the fragment detected in the MS data is followed by a sequence longer than $6 \mathrm{aa}$, are further processed to yield shorter mature peptides (e.g., AloP4, P9, P15, and P16 in Fig 3B).

Our data suggest that the C-terminal 6 aa of AloP13 are processed and trigger transcriptional reprogramming similar to other peptides in the RRNPP family of quorum sensing systems. Whereas other RRNPP quorum sensing systems were further studied and characterized using synthetic constructs or deletion mutants of the receptors and peptides $(21,27,41), P$. polymyxa is a species challenging to genetically manipulate $(46,47)$. We overcame this challenge by cloning the Alo13 system in B. subtilis and demonstrating its activity in response to the addition of the mature peptide to the medium; this approach could be used to study other Alo systems in addition to Alo13. Furthermore, future development 
of genetic systems for P. polymyxa (48) may allow, in the future, deeper mechanistic studies of Alo systems in their native host.

We found that addition of AloP13 to growing cells results in immediate down-regulation of a set of genes, including those encoding the Spo0E-like phosphatase and additional Alo peptides. These immediate expression changes are expected to be translated into a signaling cascade that may involve alteration of the phosphorylation state of additional cellular components, ultimately giving rise to a functional phenotype. The phenotype controlled by AloP13, as well as those controlled by other AloP peptides, remains to be elucidated. Revealing the full network of functional phenotypes controlled by peptide communication in P. polymyxa may enable efficient harnessing of the plant growth-promoting traits of this organism for agricultural benefit in the future.

\section{Materials and Methods}

\section{Identification of Alo systems in P. polymyxa ATCC 842}

The aa sequences of all protein-coding genes of $P$. polymyxa N.R. Smith 1105, ATCC 842 were downloaded from IMG (49) (on 31 January, 2017, IMG taxon ID: 2547132099, NCBI:txid 1036171) and scanned with TPRpred version 2.8 (32). Genes with TPRpred scores of $>75 \%$ probability of having TPR/pentatrico peptide repeats (PPRS)/SEL1 domains were further inspected. The genome environments of these genes were manually searched for downstream-annotated short ORFs with an N-terminal hydrophobic helix as predicted by the Phobius Web server (50). For two TPR-containing genes, such downstream short ORFs were identified. BlastP (51) was then used to search for homologs of these two genes among all $P$. polymyxa ATCC 842 proteins using an E-value cutoff of $1 \times 10^{-5}$. Homologs shorter than 250 aa were discarded. The remaining 16 genes were numbered aloR1-aloR16, and their cognate aloP genes were searched as above. In cases no cognate aloP gene could be identified, the last 100 bases of the aloR gene together with the 200 bases immediately downstream of the aloR were searched for short ORFs (30-50 aa) partially overlapping the $3^{\prime}$ of the aloR gene using Expasy translate tool (52). N-terminal hydrophobic helices of these AloP peptides were predicted using the Phobius Web server (50). Signal sequences were manually inferred in cases where the Phobius score was near the threshold based on homology to other AloP sequences, whose Phobius score was above the threshold.

\section{Phylogenetic analysis of Alo systems}

The aa sequences of the 16 AloR proteins identified in P. polymyxa ATCC 842 were used as a query for iterative homology search against 38,167 bacterial and archaeal genomes downloaded from the IMG database (49) on October 2017, using the "search" option in the MMseqs2 package (53) (release 6-f5a1c) with "--no-preload-max-seqs 1000 -num-iterations 3" parameters. The hits were filtered with an E-value cutoff of $<1 \times 10^{-10}$. Homologs shorter than 250 aa or homologs found in scaffolds shorter than 2,500 nt were discarded.

For the analysis appearing in Fig 2, the 234 AloR homologs found in $14 P$. polymyxa strains were aligned using the MAFFT multiple sequence alignment server version 7 with default parameters (54). The alignment was used to generate a maximum likelihood phylogenetic tree using IQ-TREE (55) version 1.6.5 including ultrafast bootstrap analysis (56) with 1,000 alignments ("-bb 1000") and using the "-m TEST" parameter to test for the best substitution model (57) (best-fit model: JTT+F+R5 chosen according to BIC). The tree was visualized using the iTOL program (58). A similar analysis with sequences of 11 rap genes from $B$. subtilis 168 used as an out-group produced the same tree structure and was used to define the tree root in Fig 2A. Clades were manually defined for AloR receptors based on the branching patterns in the phylogenetic tree (Fig 2A), as well as similarity in the cognate AloP sequence and the immediate genomic environment. For Fig 2B, the dendrogram of the Alo receptors on the vertical axis of the matrix was generated by collapsing the tree shown in Fig 2A. The dendrogram of the phylogenetic relationship between the P. polymyxa strains shown on the horizontal axis of Fig $2 \mathrm{~B}$ was generated by multiple sequence alignment and IQ-TREE analysis of the conserved GyrA protein of all 14 P. polymyxa strains, including GyrA from B. subtilis as an out-group. For the data presented in Tables S1 and S3, AloR homologs were searched for their cognate aloP genes as described for P. polymyxa ATCC 842. For the data presented in Fig S2, NCBI accessions of representative RRNPP receptors were taken from Fig S5 of reference 59 as follows: RapE (AAM51168), RapA (AAM51160), RapC (AAT75294), NprR (ABK83928), transcriptional regulator Enterococcus faecalis (T.reg E. faecalis, NP_815038), DNA-binding protein Bacillus anthracis (DNAbd B. anthracis, NP_843644), PlcR (ZP_00739149), PrgX (AAA65845), TraA BAA11197, transcriptional activator L. monocytogenes (T.act L. monocytogenes, YP_013453), transcriptional regulator L. casei (T.reg_Lcas, YP_805489), MutR (AAD56141), and RggD (AAG32546).

\section{Bacteria culture and growth conditions}

P. polymyxa ATCC 842 was obtained from the BGSC (strain 25A2) and stored in $-80^{\circ} \mathrm{C}$ as a glycerol stock. For all experiments, bacteria were first streaked on an lysogeny broth (LB) plate, grown in $30^{\circ} \mathrm{C}$ at least overnight, and colonies were used to inoculate round-bottom ventilated $15-\mathrm{ml}$ tubes containing $4-5 \mathrm{ml} \mathrm{LB}$ medium, grown at $30^{\circ} \mathrm{C}$ with $200 \mathrm{rpm}$ shaking.

\section{Preparation of growth media for MS experiments}

To search for peptide fragments secreted to the growth medium, overnight $5 \mathrm{ml}$ cultures of $P$. polymyxa or $B$. subtilis 168 were first washed by centrifuging for $5 \mathrm{~min}$ in 3,200 $\mathrm{g}$ at room temperature and resuspended in $5 \mathrm{ml}$ of chemically defined medium lacking any peptides described in reference 60 . Washed cultures were then diluted 1:100 into $250 \mathrm{ml}$ Erlenmeyer flasks with $50 \mathrm{ml}$ defined media. The cells were grown in $30^{\circ} \mathrm{C}$ with $200 \mathrm{rpm}$ shaking for $8 \mathrm{~h}$ for P. polymyxa log samples (OD 0.1) and $24 \mathrm{~h}$ for the stationary samples (three biological replicates), and $5 \mathrm{~h}$ for $B$. subtilis log samples (OD 0.3) and $8 \mathrm{~h}$ for the stationary samples (OD 0.9, one biological replicate). At the designated time point, $23 \mathrm{ml}$ samples were centrifuged for $5 \mathrm{~min}$ at 3,200g at $4^{\circ} \mathrm{C}$, and two technical replicates of $10 \mathrm{ml}$ of the supernatant for each sample were transferred to new tubes and flash-frozen immediately. 
Primers used in this study.

\begin{tabular}{lll}
\hline Name & Sequence & Use \\
\hline Spo0E_1_F & TGGCGAAAGAGGTGGGATTGA & RT-qPCR of spo0E-like gene (PPTDRAFT_04974)-primers set 1 \\
\hline Spo0E_1_R & GGGTACGCTCTGTTGTCTACGA & RT-qPCR of spo0E-like gene (PPTDRAFT_04974)-primers set 1 \\
\hline Spo0E_2_F & GAGTTGGATCGGCTCCTTAAT & RT-qPCR of spo0E-like gene (PPTDRAFT_04974)-primers set 2 \\
\hline Spo0E_2_R & CTCGTGTTGCTTCTCTTGGA & RT-qPCR of spo0E-like gene (PPTDRAFT_04974)-primers set 2 \\
\hline gyrB_F & GCCAGCGATACATTCCACTAT & RT-qPCR of gyrB gene for normalization \\
\hline gyrB_R & CACGAGAGCCTTCGACATAAA & RT-qPCR of gyrB gene for normalization \\
\hline Alo13_F & ATGGAAAATGCAACCACGATTC & $\begin{array}{l}\text { Used to amplify the Alo13 locus for cloning (start of AloR13 } \\
\text { ORF) }\end{array}$ \\
\hline Alo13_R & ATCAATAAACCTCCTGTTCGGTG & $\begin{array}{l}\text { Used to amplify the Alo13 locus for cloning (end of Spo0E } \\
\text { promoter) }\end{array}$ \\
\hline Alo13_Gib_F & CACCGAACAGGAGGTTTATTGATatgtcaaaaggagaagaactttttacag & $\begin{array}{l}\text { Used for Gibson cloning of Alo13_F and Alo13_R amplified } \\
\text { fragment (lower case letters correspond to beginning of } \\
\text { sfGFP) }\end{array}$ \\
\hline Alo13_Gib_R & GAACGAATCGTGGTTGCATTTTCCATgtttgtcctccttattagttaatcagc & $\begin{array}{l}\text { Used for Gibson cloning of Alo13_F and Alo13_R amplified } \\
\text { fragment (lower case letters correspond to RBS sequence } \\
\text { following hyper-spank promoter) }\end{array}$ \\
\hline AloP13_mut_F & TGTGCAAAGACGAAGAAGGTTTTTC & $\begin{array}{l}\text { Used for site-directed mutagenesis of AloP13 start codon ATG } \\
\text { > ACG }\end{array}$ \\
\hline AloP13_mut_R & CCCCCTTAATAATAGATTTATAAATTTC & $\begin{array}{l}\text { Used for site-directed mutagenesis of AloP13 start codon ATG } \\
\text { > ACG }\end{array}$ \\
\hline
\end{tabular}

\section{Sample preparation for MS analysis}

A method based on protein interaction with a solid phase was applied to enrich for peptides present in the supernatants. Before usage, a disposable solid phase enrichment column (8B-S100-AAK; Phenomenex), packed with an 8.5-nm pore size, modified styrene-divinylbenzene resin was equilibrated by rinsing twice with $1 \mathrm{ml}$ acetonitrile and twice with $1 \mathrm{ml}$ water. Subsequently, $10 \mathrm{ml}$ culture supernatant was loaded and unbound, potentially larger proteins were removed by washing twice with $1 \mathrm{ml}$ water. Finally, the enriched sample fraction was eluted with 0.5 $\mathrm{ml} 70 \%$ acetonitrile (vol/vol) and evaporated to dryness in a vacuum centrifuge. Samples were resuspended in $0.1 \%$ (vol/vol) acetic acid before MS analysis.

\section{MS}

The enriched peptides were loaded on an EASY-nLC 1000 system (Thermo Fisher Scientific) equipped with an in-house built $20-\mathrm{cm}$ column (inner diameter $100 \mathrm{~mm}$, outer diameter $360 \mathrm{~mm}$ ) filled with ReproSil-Pur 120 C18-AQ reversed-phase material (3 mm particles, Dr. Maisch $\mathrm{GmbH}$, Germany). Elution of peptides was executed with a nonlinear 86 min gradient from 1 to $99 \%$ solvent B (0.1\% [vol/ vol] acetic acid in acetonitrile) with a flow rate of $300 \mathrm{nl} / \mathrm{min}$ and injected online into a QExactive mass spectrometer (Thermo Fisher Scientific). The survey scan at a resolution of $R=70,000$ and $3 \times 10^{6}$ automatic gain control target with activated lock mass correction was followed by selection of the 12 most abundant precursor ions for fragmentation. Data-dependent MS/MS scans were performed at a resolution of $R=17,500$ and $1 \times 10^{5}$ automatic gain control target with a normalized collision energy of 27.5. Singly charged ions as well as ions without detected charge states or charge states higher than six were excluded from MS/MS analysis. Dynamic exclusion for $30 \mathrm{~s}$ was activated.

\section{Database search of MS results}

Identification of peptides was carried out by database search using MaxQuant 1.6.3.4 with the implemented Andromeda algorithm (61) applying the following parameters: digestion mode unspecific; variable modification, methionine oxidation, and maximal number of five modifications per peptide; activated "match-between runs" feature. The false discovery rates of peptide spectrum match, peptide, and protein level were set to 0.01 . Only unique peptides were used for identification. Two databases were used for peptide identification: a database for P. polymyxa ATCC 842 proteins downloaded from the IMG database (49) and supplemented with the sequences for the Alo systems (5,429 entries) and the reference proteome of $B$. subtilis 168 downloaded from the UniProt database (on 19 January, 2019) containing 4,264 entries. Common laboratory contaminations and reverse entries were added during MaxQuant search, and a peptide length of 5-35 aa was specified.

\section{Transcriptional response to peptides (RNA-seq experiments)}

For RNA-seq experiments, synthetic lyophilized peptides were ordered from Peptide 2.0 Inc. and Genscript Corp at purity levels of $99 \%$ for the mature AloP13 (SHGRGG), 99.2\% for the scrambled AloP13 (GRGSGH), and $81-93 \%$ for the AloP13 pro-peptide (SYFHNITIGNGSQITVSSHGRGG) and its scrambled version (VSGTRHGSFHSGIGNSGIYIQNT). The peptides were dissolved in DDW + $2 \%$ DMSO to a working stock concentration of $100 \mu \mathrm{M}$ and kept in aliquots at $-20^{\circ} \mathrm{C}$. Overnight $P$. polymyxa cultures grown in LB were diluted 1:100 into 500-ml 
Erlenmeyer flasks with $100 \mathrm{ml}$ defined medium and grown at $30^{\circ} \mathrm{C}$ with $200 \mathrm{rpm}$ shaking. At OD $\sim 0.1,45 \mathrm{ml}$ of each culture was washed by centrifuging for $5 \mathrm{~min}$ in 3,200 $\mathrm{g}$ at room temperature and resuspending the pellet in $45 \mathrm{ml}$ chemically defined medium (60). The culture was split between 5-ml tubes containing each of the tested peptides at a final concentration of $5 \mu \mathrm{M}$, or a control tube containing a similar amount of DDW + 2\% DMSO. The cultures were incubated in $30^{\circ} \mathrm{C}$ with $200 \mathrm{rpm}$ shaking for $10 \mathrm{~min}$, after which 1:10 cold stop solution ( $90 \%[\mathrm{vol} / \mathrm{vol}$ ] ethanol and $10 \%$ [vol/vol] saturated phenol) was added to the samples. The samples were centrifuged for $5 \mathrm{~min}$ at $3,200 \mathrm{~g}$ at $4^{\circ} \mathrm{C}$, the supernatant was discarded, and the pellets were immediately flash-frozen and stored in $80^{\circ} \mathrm{C}$ until RNA extraction. The experiment was conducted three times on different days to produce independent biological replicates.

Frozen bacterial pellets were lysed using the Fastprep homogenizer (MP Biomedicals) and RNA was extracted with the FastRNA PRO blue kit (116025050; MP Biomedicals) according to the manufacturer's instructions. RNA levels and integrity were assessed using Qubit RNA HS Assay Kit (Q10210; Life Technologies) and TapeStation (5067-5576; Agilent), respectively. All RNA samples were treated with TURBO DNase (AM2238; Life Technologies). Ribosomal RNA depletion and RNA-seq libraries were prepared as described in reference 62, except that all reaction volumes were reduced by a factor of four.

RNA-seq libraries were sequenced using Illumina NextSeq platform, and sequenced reads were demultiplexed using Illumina bcl2fastq module. Reads were mapped to the reference genome of $P$. polymyxa ATCC 842 downloaded from IMG (IMG taxon ID: 2547132099,65 contigs), as described in reference 62. RNA-seqmapped reads were used to generate genome-wide RNA-seq coverage maps and reads-per-gene counts.

Raw counts of reads-per-gene for each of the three biological replicates were used as input for DESeq2 package analysis using $R$ 3.6.0 (63), while accounting for batch effect (DESeqDataSet [dds] design model "design = batch + treatment"). Genes with normalized mean count $<100$ were discarded, and a significant adjusted $P$-value (false discovery rate $<0.05$ ) and fold change $>2$ or $<0.5$ were considered as the threshold for differentially expressed genes in each contrast (mature versus control and scrambled versus control). The volcano plot in Fig $4 \mathrm{~A}$ was plotted using EnhancedVolcano R package (64), based on the results of the DESeqs2 analysis.

\section{RT-qPCR analysis}

Bacteria were treated with the AloP13 mature peptide, scrambled mature peptide, and no peptide as described for the RNA-seq experiments, and cell pellets were collected from two biological replicates. Total RNA was extracted from the cells as described above, and $1 \mu \mathrm{g}$ of DNase-treated RNA was then reverse-transcribed using high-capacity cDNA reverse-transcription kit with random primers according to the manufacturer's instructions (Applied Biosystems). Quantitative PCR was performed with SYBR Green PCR Master Mix (Applied Biosystems/Thermo Fisher Scientific) and gene-specific primers listed below in triplicates, on Viia7 platform (Applied Biosystems). Error bars indicate SD of 2-3 measurements for each sample, and the housekeeping gene gyrB was used for normalization.

\section{Cloning of the Alo13 locus in B. subtilis}

The Alo13 locus including the aloR13 ORF, aloP13 ORF, and the intergenic region until the SPOOE-like ORF was amplified using primers Alo13_F and Alo13_R (listed below). The fragment was cloned using NEBuilder HiFi DNA Assembly Master Mix (New England Biolabs) with primers Alo13_Gib_F and Alo13_Gib_R under an IPTG-inducible hyper-spank promoter with a super-folder GFP (sfGFP) into an AmyE integration cassette with ampicillin and spectinomycin resistance and transformed into chemically competent Escherichia coli DH $5 \alpha$. The plasmids were then extracted and transformed into B. subtilis BEST7003 as described before (65). To introduce a point mutation in the start codon of AloP13, primers AloP13_mut_F and AloP13_mut_R were used with Q5 Site-Directed Mutagenesis Kit (New England Biolabs) according to the manufacturer's instructions. The integrity of the sequence was verified by Sanger sequencing.

\section{Fluorescence assay}

Overnight LB cultures of B. subtilis BEST7003 with the Alo13-GFP integrated construct were diluted 1:100 into defined medium with the synthesized peptides at various concentrations, and with 0 or $100 \mu$ M IPTG (Isopropyl $\beta$-D-1-thiogalactopyranoside) as an inducer. Optical density and fluorescence measurements were performed in triplicates using a TECAN Infinite 200 plate reader in a 96-well plate.

\section{Data Availability}

All MS data (Fig 3 and Table S4) have been deposited to the ProteomeXchange Consortium via the PRIDE (66) partner repository with the dataset identifier PXD015319. All raw RNA-seq datasets (Fig 4 and Tables S5 and S6) were deposited in the European Nucleotide Database (ENA), study accession no. PRJEB34369.

\section{Supplementary Information}

Supplementary Information is available at https://doi.org/10.26508/lsa. 202000847

\section{Acknowledgements}

We thank Yael Helman, Yaara Oppenheimer-Shaanan, Ohad Herches, Alon Savidor, Etai Rotem, Gilad Yaakov, Tabitha Bucher, Maya Schuldiner, Nofar Mor, Daniel Zeigler, and Jürgen Bartel for their expertise and technical assistance. We thank the Sorek lab members for fruitful discussions and helpful suggestions. R Sorek was supported, in part, by the Israel Science Foundation (personal grant 1360/16), the European Research Council (ERC) (grant ERC-CoG 681203), the German Research Council (DFG) priority program SPP 2002 (grant SO 1611/1-1), and the Knell Family Center for Microbiology. M Voichek is a Clore Scholar and was supported by the Clore Israel Foundation. $S$ Maaß and D Becher were supported by the German Research Council (DFG) priority program SPP 2002 (grant BE 3869/5-1). 


\section{Author Contributions}

M Voichek: conceptualization, data curation, software, formal analysis, validation, investigation, visualization, methodology, and writing-original draft, review, and editing.

S Maaß: software, formal analysis, validation, investigation, and methodology.

T Kroniger: methodology.

D Becher: software, supervision, funding acquisition, validation, investigation, and methodology.

R Sorek: conceptualization, resources, supervision, funding acquisition, investigation, visualization, methodology, project administration, and writing-original draft, review, and editing.

\section{Conflict of Interest Statement}

The authors declare that they have no conflict of interest.

\section{References}

1. Genersch E (2010) American Foulbrood in honeybees and its causative agent, Paenibacillus larvae. J Invertebr Pathol 103: S10-S19. doi:10.1016/ j.jip.2009.06.015

2. Be'er A, Strain SK, Hernández RA, Ben-Jacob E, Florin E-L (2013) Periodic reversals in Paenibacillus dendritiformis swarming. I Bacteriol 195: 2709-2717. doi:10.1128/JB.00080-13

3. Ingham CJ, Ben Jacob E (2008) Swarming and complex pattern formation in Paenibacillus vortex studied by imaging and tracking cells. BMC Microbiol 8: 36. doi:10.1186/1471-2180-8-36

4. Jeong H, Choi S-K, Ryu C-M, Park S-H (2019) Chronicle of a soil bacterium: Paenibacillus polymyxa E681 as a tiny guardian of plant and human health. Front Microbiol 10: 467. doi:10.3389/fmicb.2019.00467

5. Timmusk S, Wagner EG (1999) The plant-growth-promoting rhizobacterium Paenibacillus polymyxa induces changes in Arabidopsis thaliana gene expression: A possible connection between biotic and abiotic stress responses. Mol Plant Microbe Interact 12: 951-959. doi:10.1094/mpmi.1999.12.11.951

6. Weselowski B, Nathoo N, Eastman AW, MacDonald J, Yuan ZC (2016) Isolation, identification and characterization of Paenibacillus polymyxa CR1 with potentials for biopesticide, biofertilization, biomass degradation and biofuel production. BMC Microbiol 16: 244. doi:10.1186/ s12866-016-0860-y

7. Choi SK, Park SY, Kim R, Kim SR, Lee CH, Kim JF, Park SH (2009) Identification of a polymyxin synthetase gene cluster of Paenibacillus polymyxa and heterologous expression of the gene in Bacillus subtilis. J Bacteriol 191: 3350-3358. doi:10.1128/jb.01728-08

8. Lebuhn M, Heulin T, Hartmann A (2006) Production of auxin and other indolic and phenolic compounds by Paenibacillus polymyxa strains isolated from different proximity to plant roots. FEMS Microbiol Ecol 22: 325-334. doi:10.1111/j.1574-6941.1997.tb00384.x

9. Grady EN, MacDonald J, Liu L, Richman A, Yuan Z-C (2016) Current knowledge and perspectives of Paenibacillus: A review. Microb Cell Fact 15: 203. doi:10.1186/s12934-016-0603-7

10. Hong CE, Kwon SY, Park JM (2016) Biocontrol activity of Paenibacillus polymyxa AC-1 against Pseudomonas syringae and its interaction with Arabidopsis thaliana. Microbiol Res 185: 13-21. doi:10.1016/ j.micres.2016.01.004

11. Luo Y, Cheng Y, Yi J, Zhang Z, Luo Q, Zhang D, Li Y (2018) Complete genome sequence of industrial biocontrol strain Paenibacillus polymyxa HY96-2 and further analysis of its biocontrol mechanism. Front Microbiol 9: 1520 doi:10.3389/fmicb.2018.01520

12. Ng W-L, Bassler BL (2009) Bacterial quorum-sensing network architectures. Annu Rev Genet 43: 197-222. doi:10.1146/annurev-genet102108-134304

13. Schuster M, Greenberg EP (2006) A network of networks: Quorumsensing gene regulation in Pseudomonas aeruginosa. Int J Med Microbiol 296: 73-81. doi:10.1016/j.ijmm.2006.01.036

14. Davey ME, Caiazza NC, O'Toole GA (2003) Rhamnolipid surfactant production affects biofilm architecture in Pseudomonas aeruginosa PAO1. J Bacteriol 185: 1027-1036. doi:10.1128/jb.185.3.1027-1036.2003

15. Brurberg MB, Nes IF, Eijsink VG (1997) Pheromone-induced production of antimicrobial peptides in Lactobacillus. Mol Microbiol 26: 347-360. doi:10.1046/j.1365-2958.1997.5821951.x

16. van der Ploeg JR (2005) Regulation of bacteriocin production in Streptococcus mutans by the quorum-sensing system required for development of genetic competence. J Bacteriol 187: 3980-3989. doi:10.1128/JB.187.12.3980-3989.2005

17. Hoover SE, Perez AJ, Tsui H-CT, Sinha D, Smiley DL, DiMarchi RD, Winkler ME, Lazazzera BA (2015) A new quorum-sensing system (TprA/PhrA) for Streptococcus pneumoniae D39 that regulates a lantibiotic biosynthesis gene cluster. Mol Microbiol 97: 229-243. doi:10.1111/mmi.13029

18. Grossman AD (1995) Genetic networks controlling the initiation of sporulation and the development of genetic competence in Bacillus subtilis. Annu Rev Genet 29: 477-508. doi:10.1146/ annurev.ge.29.120195.002401

19. Neiditch MB, Capodagli GC, Prehna G, Federle MJ (2017) Genetic and structural analyses of RRNPP intercellular peptide signaling of grampositive bacteria. Annu Rev Genet 51: 311-333. doi:10.1146/annurevgenet-120116-023507

20. Lanigan-Gerdes S, Dooley AN, Faull KF, Lazazzera BA (2007) Identification of subtilisin, Epr and Vpr as enzymes that produce CSF, an extracellular signalling peptide of Bacillus subtilis. Mol Microbiol 65: 1321-1333. doi:10.1111/j.1365-2958.2007.05869.x

21. Stephenson S, Mueller C, Jiang M, Perego M (2003) Molecular analysis of Phr peptide processing in Bacillus subtilis. I Bacteriol 185: 4861-4871. doi:10.1128/jb.185.16.4861-4871.2003

22. Perego M, Higgins CF, Pearce SR, Gallagher MP, Hoch JA (1991) The oligopeptide transport system of Bacillus subtilis plays a role in the initiation of sporulation. Mol Microbiol 5: 173-185. doi:10.1111/j.13652958.1991.tb01838.x

23. Slamti L, Lereclus D (2019) The oligopeptide ABC-importers are essential communication channels in Gram-positive bacteria. Res Microbiol 170: 338-344. doi:10.1016/j.resmic.2019.07.004

24. Do H, Kumaraswami M (2016) Structural mechanisms of peptide recognition and allosteric modulation of gene regulation by the RRNPP family of quorum-sensing regulators. J Mol Biol 428: 2793-2804. doi:10.1016/j.jmb.2016.05.026

25. Burbulys D, Trach KA, Hoch JA (1991) Initiation of sporulation in B. subtilis is controlled by a multicomponent phosphorelay. Cell 64: 545-552. doi:10.1016/0092-8674(91)90238-t

26. Pottathil M, Lazazzera BA (2003) The extracellular Phr peptide-Rap phosphatase signaling circuit of Bacillus subtilis. Front Biosci 8: d32-d45. doi:10.2741/913

27. Slamti L, Lereclus D (2002) A cell-cell signaling peptide activates the PlcR virulence regulon in bacteria of the Bacillus cereus group. EMBO I 21: 4550-4559. doi:10.1093/emboj/cdf450

28. Erez Z, Steinberger-Levy I, Shamir M, Doron S, Stokar-Avihail A, Peleg Y Melamed S, Leavitt A, Savidor A, Albeck S, et al (2017) Communication between viruses guides lysis-lysogeny decisions. Nature 541: 488-493. doi:10.1038/nature21049 
29. Stokar-Avihail A, Tal N, Erez Z, Lopatina A, Sorek R (2019) Widespread utilization of peptide communication in phages infecting soil and pathogenic bacteria. Cell Host Microbe 25: 746-755.e5. doi:10.1016/ j.chom.2019.03.017

30. Core L, Perego M (2003) TPR-mediated interaction of RapC with ComA inhibits response regulator-DNA binding for competence development in Bacillus subtilis. Mol Microbiol 49: 1509-1522. doi:10.1046/j.13652958.2003.03659.x

31. Jeong H, Park S-Y, Chung W-H, Kim SH, Kim N, Park S-H, Kim JF (2011) Draft genome sequence of the Paenibacillus polymyxa type strain (ATCC 842T), a plant growth-promoting bacterium. J Bacteriol 193: 5026-5027. doi:10.1128/jb.05447-11

32. Karpenahalli MR, Lupas AN, Söding J (2007) TPRpred: A tool for prediction of TPR-, PPR- and SEL1-like repeats from protein sequences. BMC Bioinformatics 8: 2. doi:10.1186/1471-2105-8-2

33. Fekkes P, Driessen AJ (1999) Protein targeting to the bacterial cytoplasmic membrane. Microbiol Mol Biol Rev 63: 161-173. doi:10.1128/ mmbr.63.1.161-173.1999

34. Even-Tov E, Bendori SO, Pollak S, Eldar A (2016) Transient duplicationdependent divergence and horizontal transfer underlie the evolutionary dynamics of bacterial cell-cell signaling. PLoS Biol 14: e2000330. doi:10.1371/journal.pbio.2000330

35. Perego M (1997) A peptide export-import control circuit modulating bacterial development regulates protein phosphatases of the phosphorelay. Proc Natl Acad Sci U S A 94: 8612-8617. doi:10.1073/ pnas.94.16.8612

36. Lanigan-Gerdes S, Briceno G, Dooley AN, Faull KF, Lazazzera BA (2008) Identification of residues important for cleavage of the extracellular signaling peptide CSF of Bacillus subtilis from its precursor protein. J Bacteriol 190: 6668-6675. doi:10.1128/jb.00910-08

37. Dalbey RE, Wang P, van Dijl JM (2012) Membrane proteases in the bacterial protein secretion and quality control pathway. Microbiol Mol Biol Rev 76: 311-330. doi:10.1128/mmbr.05019-11

38. Ravipaty S, Reilly JP (2010) Comprehensive characterization of methicillin-resistant Staphylococcus aureus subsp. aureus COL secretome by two-dimensional liquid chromatography and mass spectrometry. Mol Cell Proteomics 9: 1898-1919. doi:10.1074/ mcp.m900494-mcp200

39. Koskinen VR, Emery PA, Creasy DM, Cottrell JS (2011) Hierarchical clustering of shotgun proteomics data. Mol Cell Proteomics 10: M110.003822. doi:10.1074/mcp.m110.003822

40. Perego M, Hoch JA (1991) Negative regulation of Bacillus subtilis sporulation by the Spo0E gene product. I Bacteriol 173: 2514-2520. doi:10.1128/jb.173.8.2514-2520.1991

41. Parashar V, Konkol MA, Kearns DB, Neiditch MB (2013) A plasmidencoded phosphatase regulates Bacillus subtilis biofilm architecture, sporulation, and genetic competence. J Bacteriol 195: 2437-2448. doi:10.1128/jb.02030-12

42. Eastman AW, Heinrichs DE, Yuan ZC (2014) Comparative and genetic analysis of the four sequenced Paenibacillus polymyxa genomes reveals a diverse metabolism and conservation of genes relevant to plant-growth promotion and competitiveness. BMC Genomics 15: 1-22. doi:10.1186/1471-2164-15-851

43. Qian Y, Kando CK, Thorsen L, Larsen N, Jespersen L (2015) Production of autoinducer-2 by aerobic endospore-forming bacteria isolated from the West African fermented foods. FEMS Microbiol Lett 362: 1-7. doi:10.1093/ femsle/fnv186

44. Huang E, Yousef AE (2015) Biosynthesis of paenibacillin, a lantibiotic with $\mathrm{N}$-terminal acetylation, by Paenibacillus polymyxa. Microbiol Res 181: 15-21. doi:10.1016/j.micres.2015.08.001

45. Mirouze N, Parashar V, Baker MD, Dubnau DA, Neiditch MB (2011) An atypical Phr peptide regulates the developmental switch protein RapH.J Bacteriol 193: 6197-6206. doi:10.1128/jb.05860-11
46. Timmusk S, Kim S-B, Nevo E, El Daim IA, Ek B, Bergquist J, Behers L (2015) Sfp-type PPTase inactivation promotes bacterial biofilm formation and ability to enhance wheat drought tolerance. Front Microbiol 6: 387. doi:10.3389/fmicb.2015.00387

47. Kim S-B, Timmusk S (2013) A simplified method for gene knockout and direct screening of recombinant clones for application in Paenibacillus polymyxa. PLoS One 8: e68092. doi:10.1371/journal.pone.0068092

48. Li H, Ding Y, Zhao J, Ge R, Qiu B, Yang X, Yao L, Liu K, Wang C, Du B (2019) Identification of a native promoter P LH-77 for gene expression in Paenibacillus polymyxa. J Biotechnol 295: 19-27. doi:10.1016/ j.jbiotec.2019.02.002

49. Chen I-MA, Chu K, Palaniappan K, Pillay M, Ratner A, Huang J, Huntemann M, Varghese N, White JR, Seshadri R, et al (2019) IMG/M v.5.0: An integrated data management and comparative analysis system for microbial genomes and microbiomes. Nucleic Acids Res 47: D666-D677. doi:10.1093/nar/gky901

50. Käll L, Krogh A, Sonnhammer ELLL (2004) A combined transmembrane topology and signal peptide prediction method. J Mol Biol 338: 1027-1036. doi:10.1016/j.jmb.2004.03.016

51. Altschul SF, Gish W, Miller W, Myers EW, Lipman DJ (1990) Basic local alignment search tool. J Mol Biol 215: 403-410. doi:10.1016/s00222836(05)80360-2

52. Gasteiger E, Gattiker A, Hoogland C, Ivanyi I, Appel RD, Bairoch A (2003) ExPASy: The proteomics server for in-depth protein knowledge and analysis. Nucleic Acids Res 31: 3784-3788. doi:10.1093/nar/gkg563

53. Steinegger M, Söding J (2017) MMseqs2 enables sensitive protein sequence searching for the analysis of massive data sets. Nat Biotechnol 35: 1026-1028. doi:10.1038/nbt.3988

54. Katoh K, Rozewicki J, Yamada KD (2017) MAFFT online service: Multiple sequence alignment, interactive sequence choice and visualization. Brief Bioinform 20: 1160-1166. doi:10.1093/ bib/bbx108

55. Nguyen LT, Schmidt HA, Von Haeseler A, Minh BQ (2015) IQ-TREE: A fast and effective stochastic algorithm for estimating maximum-likelihood phylogenies. Mol Biol Evol 32: 268-274. doi:10.1093/molbev/msu300

56. Hoang DT, Chernomor O, Von Haeseler A, Minh BQ, Vinh LS (2018) UFBoot2: Improving the ultrafast bootstrap approximation. Mol Biol Evol 35: 518-522. doi:10.1093/molbev/msx281

57. Kalyaanamoorthy S, Minh BQ, Wong TKF, Von Haeseler A, Jermiin LS (2017) ModelFinder: Fast model selection for accurate phylogenetic estimates. Nat Methods 14: 587-589. doi:10.1038/nmeth.4285

58. Letunic I, Bork P (2016) Interactive tree of life (iTOL) V3: An online tool for the display and annotation of phylogenetic and other trees. Nucleic Acids Res 44: W242-W245. doi:10.1093/nar/gkw290

59. Declerck N, Bouillaut L, Chaix D, Rugani N, Slamti L, Hoh F, Lereclus D, Arold ST (2007) Structure of PICR: Insights into virulence regulation and evolution of quorum sensing in Gram-positive bacteria. Proc Natl Acad Sci U S A 104: 18490-18495. doi:10.1073/pnas.0704501104

60. Agata N, Ohta M, Mori M, Shibayama K (1999) Growth conditions of and emetic toxin production by Bacillus cereus in a defined medium with amino acids. Microbiol Immunol 43: 15-18. doi:10.1111/j.13480421.1999.tb02367.x

61. Cox J, Hein MY, Luber CA, Paron I, Nagaraj N, Mann M (2014) Accurate proteome-wide label-free quantification by delayed normalization and maximal peptide ratio extraction, termed MaxLFQ. Mol Cell Proteomics 13: 2513-2526. doi:10.1074/mcp.m113.031591

62. Dar D, Shamir M, Mellin JR, Koutero M, Stern-Ginossar N, Cossart P, Sorek $\mathrm{R}$ (2016) Term-seq reveals abundant ribo-regulation of antibiotics resistance in bacteria. Science 352: aad9822. doi:10.1126/ science.aad9822

63. Love MI, Huber W, Anders S (2014) Moderated estimation of fold change and dispersion for RNA-seq data with DESeq2. Genome Biol 15: 550. doi:10.1186/s13059-014-0550-8 
64. Blighe K (2019) Publication-ready volcano plots with enhanced colouring and labeling R-Package 1.2.0.

65. Doron S, Melamed S, Ofir G, Leavitt A, Lopatina A, Keren M, Amitai G, Sorek $\mathrm{R}$ (2018) Systematic discovery of antiphage defense systems in the microbial pangenome. Science 359: earr4120. doi:10.1126/ science.aar4120

66. Vizcaino JA, Csordas A, del-Toro N, Dianes JA, Griss J, Lavidas I, Mayer G, Perez-Riverol Y, Reisinger F, Ternent T, et al (2016) 2016 update of the
PRIDE database and its related tools. Nucleic Acids Res 44: D447-D456. doi:10.1093/nar/gkv1145

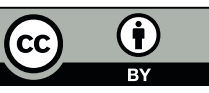

License: This article is available under a Creative Commons License (Attribution 4.0 International, as described at https://creativecommons.org/ licenses/by/4.0/). 